\title{
Nanostructure Evolution in AA7075 Alloy Produced by Solid State Additive Manufacturing - Additive Friction Stir - Deposition
}

\author{
Rekha M Y ${ }^{1}$, Dustin Avery², Paul G Allison², J. Brian Jordon² and Luke Brewer ${ }^{3}$ \\ ${ }^{1}$ Metallurgical and Materials Engineering, University of Alabama, Tuscaloosa, AL, USA, Tuscaloosa, \\ Alabama, United States, ${ }^{2}$ Mechanical Engineering, University of Alabama, Tuscaloosa, AL, USA, Tuscaloosa, \\ Alabama, United States, ${ }^{3}$ University of Alabama, Tuscaloosa, Alabama, United States
}

Solid-state additive manufacturing is a promising technology for producing complex geometry alloys for aerospace applications [1]. Among metal additive manufacturing technologies, additive friction stir-deposition (AFS-D) provides an innovative solution for the fabrication and repair of high strength Al-alloy components [2]. In the AFS-D process, feedstock material is deposited in a layer-by-layer fashion using a hollow, rotating tool onto a substrate [3]. When the hollow rotating tool comes in contact with the substrate, frictional heat and pressure is generated which creates a metallurgical bond between the feedstock material and the substrate. For the AA7075 alloy, the nanoscale precipitates $\operatorname{MgZn}_{2}\left(\eta^{\prime}\right)$ and $\mathrm{MgZn}_{2}(\eta)$ control the strength of the material and may be dissolved and reformed by the thermal-mechanical AFS-D process. In this study, we investigate the evolution of size, phase constitution and spatial distribution of nanoscale precipitates in as-deposited and heat-treated AA7075 material.

Solid AA7075-T651 feedstock rod with a nominal composition of (wt.\%) Al-5.6Zn-2.6Mg-1.6Cu was deposited onto a substrate (rolled plate with the same composition as the feedstock rod). Feedstock rod dimension was $9.5 \mathrm{~mm}$ (square geometry) while the damaged plate substrate with milled grove through the centre was $6.35 \mathrm{~mm}$ thick. Parameters used for the deposition were $225 \mathrm{RPM}$ tool rotational speed, 50.8 $\mathrm{mm} / \mathrm{min}$ traversing velocity and $50.8 \mathrm{~mm} / \mathrm{min}$ feedstock feed rate. Sections of material produced by AFS-D were subsequently heat-treated to recover the T6 temper [4]. The heat-treatment schedule included solutionizing treatment at $490^{\circ} \mathrm{C}$ for $1 \mathrm{hr}$ followed by water quench and then age hardening at $120^{\circ} \mathrm{C}$ for $24 \mathrm{hr}$.

Figures 1(a), (b) and (c) show the TEM bright field images of AFS-D, heat-treated AFS-D and heat affected zone (HAZ) AFS-D samples respectively. All the samples contained finely distributed $\mathrm{Zn}-\mathrm{Mg}-\mathrm{Cu}$ rich precipitates (dark precipitates in these images). Average size of the precipitates in as-deposited AFS-D, heattreated AFS-D and HAZ AFS-D samples were $8.84 \pm 2.8 \mathrm{~nm}, 7.18 \pm 2.5 \mathrm{~nm}$ and $8.27 \pm 2.9 \mathrm{~nm}$ respectively. The heat treated sample (Figure 1(b)) showed highest density of fine precipitates. The HAZ sample (Figure 1(c)) showed similar sized precipitates as AFS-D sample but with lower density. Few relatively larger sized precipitates were also be observed in HAZ sample due to the aging during the AFS-D process. The as-deposited AFS-D sample (Figure 1(a)) showed the finest precipitates, which were fewer in amount than those observed in the case of the heat treated sample. It is speculated that these precipitates formed due to natural aging of the sample after deposition. The SAED pattern from as-deposited material (Figure 1(d)) shows diffraction rings corresponding to randomly oriented ( $\mathrm{AlZn}) \mathrm{Mg}_{4} \mathrm{Zn}_{10}$ precipitates. The S-phase $\left(\mathrm{Al}_{2} \mathrm{CuMg}\right), \mathrm{MgZn} \mathrm{n}_{2}(\eta)$ and $\operatorname{MgZn}_{2}(\eta)$ phases are also present in this SAED pattern. In the heat affected zones caused by multiple passes of the tool (Figure 1(e)), the SAED pattern reveals the presence of $\mathrm{MgZn}_{2}(\eta)$ and $\mathrm{MgZn}_{2}(\eta$ ') phases along with the presence of $(\mathrm{AlZn}) \mathrm{Mg}_{4} \mathrm{Zn}_{10}$ phase. These diffraction patterns revealed that the heat-treated sample underwent in situsolutionization and re-precipitation of strengthening phases. For ex situ heat treated material, the SAED pattern (Figure 1(f)), reveals the presence of S-phase $\left(\mathrm{Al}_{2} \mathrm{CuMg}\right), \mathrm{MgZn}_{2}(\eta)$ and $(\mathrm{AlZn}) \mathrm{Mg}_{4} \mathrm{Zn}_{10}$ phases. With respect to the spatial location of the precipitates it should be further noted that the as-deposited AFS-D repair sample (Figure 2(a)) also contains large sized precipitates (127.94 $\pm 38.2 \mathrm{~nm}$ ) which are discontinuously arranged over the grain-boundary region and within the grains in the microstructure. In contrast, the heat-treated AFS-D sample (Figure 2(b)) exhibited a distinctly different microstructure in which the fine sized precipitates $(15.85 \pm 5.1 \mathrm{~nm})$ are distributed along the grain-boundaries, while the relatively 
larger size precipitates $(95.27 \pm 25.9 \mathrm{~nm})$ are distributed within the grains away from the grain-boundary region.

In the near future, atom probe tomography will be utilized to measure the chemical composition of these precipitates and to analyse the location and distribution of precipitate in as-deposited and heat-treated AA7075 alloys.

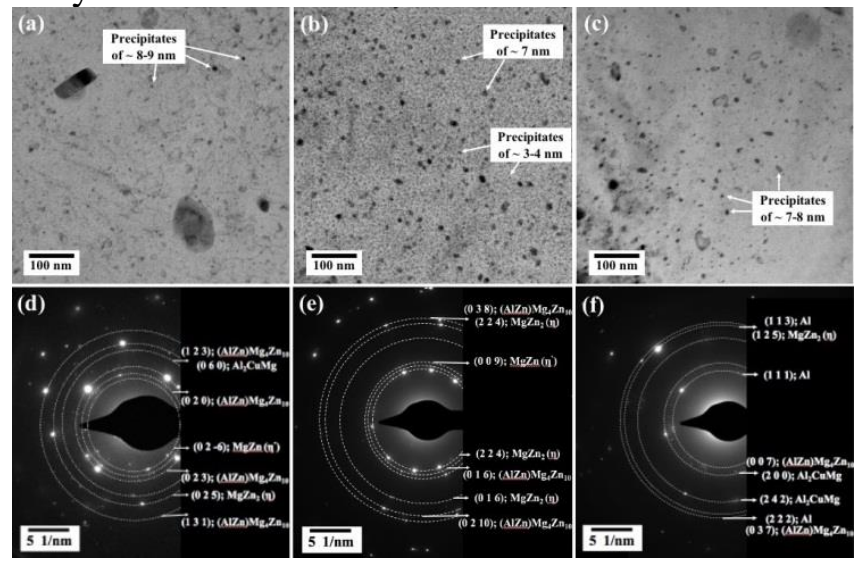

Figure 1. Representative TEM bright field images of (a) as-deposited AFS-D repair, (b) heat-treated AFS-D repair and (c) HAZ AFS-D. SAD patterns obtained from (d) as-deposited AFS-D repair, (e) heat-treated AFSD repair and (f) HAZ AFS-D. The dotted lines in the SAD pattern are viewing aid.

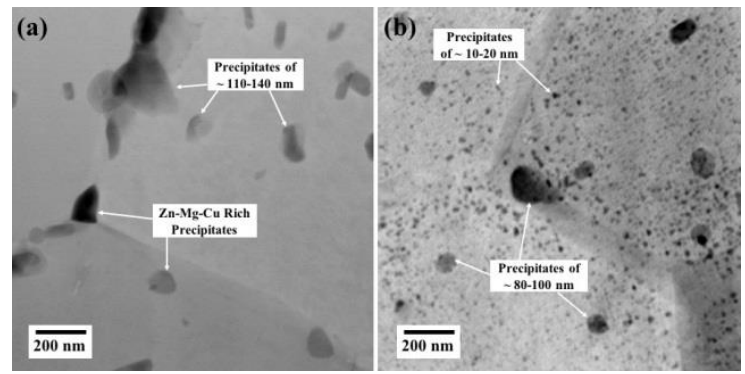

Figure 2. Representative TEM bright field images of (a) as-deposited AFS-D repair and (b) heat-treated AFSD repair samples.

\section{References}

[1] J. Liu etal, Laser Additive Manufacturing, Woodhead Publishing (2017) p. 351.

[2] B. J. Phillips et al, Materialia7 (2019) p. 100387.

[3] D. Z. Avery et al, Metall. Mater. Trans. A 51 (2020) p. 2778.

[4] ASM International, ASM handbook 4 (1991) p.229. 